1 Tribunal de Justiça do Estado do Rio de Janeiro (TJRJ) - Rio de Janeiro (RJ), Brasil.

anaazevedo@tjrj.jus.br

2 Fundação Oswaldo Cruz (Fiocruz), Escola Nacional de Saúde Pública Sergio Arouca (Ensp), Departamento de Epidemiologia e Métodos Quantitativos em Saúde (DEMQS) - Rio de Janeiro (RJ), Brasil.

\section{O eclipse da interseção entre público e privado: o financiamento público do subsetor privado de saúde à luz da Constituição Federal}

\author{
The eclipse between public and private: public financing of the private \\ sector in light of the Brazilian Constitution
}

Ana Paula Azevedo Gomes', Elvira Maria Godinho de Maciel2

DOI: 10.1590/0103-110420195421

RESUMO O desenho do sistema de saúde suplementar não pode ser feito de forma paralela, mas em uma verdadeira zona de interseção com o Sistema Único de Saúde (SUS) dentro do esquadro Constitucional. Os caminhos entre os subsistemas público e privado revelam que, apesar do movimento da Reforma Sanitária, coexistem de forma simbiótica o SUS e o sistema suplementar, em um verdadeiro concubinato de recursos e de pacientes, como uma resultante da estruturação do sistema de saúde em conflito com as políticas públicas de saúde traçadas. A dimensão dos contratos privados de saúde não se exaure nas relações entre usuários e operadoras: existe um interesse que é público, existem relações diversas, não lineares que determinam o cuidado prestado; e, por isso, o olhar e a atuação do administrador público não podem se limitar a verificar o equilíbrio financeiro dos contratos de saúde, mas devem alcançar e regular a qualidade do cuidado, de forma a resguardar em todos e em cada um o interesse público neles contidos.

PALAVRAS-CHAVE Sistema Único de Saúde. Financiamento governamental. Saúde suplementar. Regulação e fiscalização em saúde.

ABSTRACT The design of the supplementary health system cannot be done in parallel, but in a true intersection zone with the Unified Health System (SUS), within the Constitutional scope. The paths between the public and private subsystems reveal that, despite the Health Reform movement, the SUS and the supplementary system coexist symbiotically, in true concubinage of resources and patients, as a result of the structuring of the health system in conflict with the public health policies outlined. The dimension of private health contracts is not exhausted in the relationships between users and operators: there is a public interest, there are diverse, nonlinear relationships that determine the care provided, and therefore the look and performance of the public administrator cannot be limited to verifying the financial equilibrium of health contracts, but must achieve and regulate the quality of care to safeguard the public interest contained therein.

KEYWORDS Unified Health System. Financing government. Supplemental health. Health care coordination and monitoring. 


\section{Introdução}

O presente ensaio é, em verdade, um recorte de estudo preliminar, mas que tem em comum um mesmo objetivo: revelar o público dentro do privado, sugerindo uma leitura do sistema de saúde suplementar vinculada e a partir do Sistema Único de Saúde (SUS), buscando na interação desses dois nichos um verdadeiro sistema, em uma relação de continência, de dependência, e, sobremaneira, de afetação. Mais do que distinguir, o objetivo é vincular, é ligar, é deixar permear as leituras do sistema suplementar pelo conteúdo público que entendemos que nele existe.

As demandas sobre saúde levadas ao Poder Judiciário, quando envolvem o sistema de saúde suplementar, assumem características próprias, mas também encontram suas principais questões na restrição de acesso, na integralidade do tratamento e, de forma particular, na seleção de nicho de mercado pelas operadoras. Diferentemente do sistema público, aqui o limite à pretensão de saúde e à integralidade do cuidado não é a coletividade dos usuários, mas o próprio contrato de prestação de serviços firmado entre a operadora e cada consumidor. No entanto, seriam eles, os contratantes, os únicos afetados por esses contratos? $\mathrm{O}$ interesse nessas relações é individual apenas?

Esses contratos vêm sendo analisados pelo Poder Judiciário sempre sob a perspectiva operadora-usuário, orbitando a discussão dentro da proteção às relações de consumo, sob a égide das Leis $n^{0} 8.078 / 90^{1} \mathrm{e} \mathrm{n}^{0}$ 9.656/98². Isso significa reconhecer a fragilidade de um grupo econômico em relação a outro, fazendo com que, individualmente, esses contratos possam ser balizados de forma a equalizar essa relação vertical entre o consumidor e as operadoras, resguardando direitos que não pertencem apenas a um indivíduo, mas a um grupo de sujeitos que podem ser considerados de forma coletiva. Esses contratos ganham assim uma dimensão maior, não apenas individual, mas coletiva. Ainda, porém, sob a tutela de interesses privados.
Para o Administrador Público, o olhar sobre os contratos de planos de saúde e seguros de saúde se dirige quase que exclusivamente à manutenção do equilíbrio financeiro desses contratos. Todavia, ao atuar como agência de mercado, mas não de assistência, a Agência Nacional de Saúde (ANS) direciona o olhar investigativo ao mercado de saúde privado, e afasta a discussão sobre saúde e estrutura social, excluindo, pela perspectiva econômica, o olhar para a atuação do setor privado como ator que interage com as políticas públicas. Recaímos nas luzes e sombras do diálogo requerido entre público e privado. $\mathrm{E}$ as zonas de interseção.

Se é verdade que a Reforma Sanitária conseguiu eleger o sistema universalista dentro da Constituição da República ${ }^{3}$, garantindo a saúde como direito universal por meio do SUS, é verdade também que, ao lado desse sistema, restou uma estrutura que em muito se aproxima do modelo assistencialista, privado e não regulado - ou insuficientemente regulado.

Não olhar o sistema de saúde privado é ignorar as contradições que o sistema de saúde brasileiro apresenta em sua totalidade; pensar o sistema de saúde privado é buscar entender como um sistema de saúde que é único pode ser dois; como sendo dois, deve ser ainda, e em alguma medida, único; é questionar como e para quem ele foi desenhado.

O ocultamento dessa questão favorece uma verdadeira apropriação do espaço público de saúde pelo sistema privado, na contramão do que pretendia a Reforma Sanitária, criando, na ausência do diálogo, uma dicotomia entre público e privado 4 .

É preciso redirecionar o olhar sobre o sistema de saúde suplementar para uma compreensão orgânica, integral, vinculada e a partir da Constituição. Existe, nesses contratos, um interesse público latente: público porque afeta um quarto da população, público porque recebe subsídio do governo, público porque seu objeto é a saúde e a saúde dá a dimensão da vida que se vive, desenhando assim a própria existência. 
O enquadramento do direito à saúde como direito fundamental carrega a compreensão de que dentro, fora e por meio do Estado se tecem e se reconhecem relações que são determinantes para a apreensão do sistema de saúde suplementar a partir e dentro das políticas de saúde; traz a compreensão de que essas políticas são determinadas pelas estruturas, pelos atores, pelas relações entre umas e outros, são condicionadas, acondicionadas e, ao mesmo tempo, condicionantes.

A compreensão da dupla atuação do Estado, como palco e como ator social, implica reconhecer que, como instituição, ele cria políticas públicas, isto é, escolhe módulo, direção e sentido, e, com isso, determina a trajetória do sistema de saúde, trazendo para a sua compreensão dois argumentos: contingência histórica e dependência de trajetória. Para Menicucci5 ${ }^{5}$ os desenhos de políticas públicas alteram os processos políticos e modelam identidades de grupo.

Entender o desenho da saúde suplementar requer que se observem os lugares e momentos em que ele se desenvolveu, e aqui é preciso ter em mente que a opção ideológica por um sistema de saúde único veio paradoxalmente acompanhada de uma estrutura desenhada de acordo com um modelo meritocrático e assistencialista.

A força do setor privado vem justamente do incentivo público recebido: no começo, por meio do Instituto Nacional de Previdência Social (INPS) e do Instituto Nacional de Assistência Médica e Previdência Social (Inamps); depois, subsidiado pelo Fundo de Apoio ao Desenvolvimento Social (FAS) - o setor privado pode garantir custeio tendo recebido aporte financeiro a juro baixo para a expansão de sua rede:

Em tal ambiente de estufa, sob condições ideais de instalação e crescimento, protegido das incertezas concorrenciais, desenvolveu-se na área da saúde um tipo de empresário bastante conhecido em outros setores da economia brasileira, cujo investimento e demanda estão intimamente vinculados à política governamenta|6(148)
Se o 'incentivo' público foi o ponto de partida para o desenvolvimento do setor privado, foi a ausência de intervenção que possibilitou, em um segundo momento, o desenvolvimento autônomo e a expansão desse setor, que a partir daí se coloca como ator, criando vetores que interagem na produção das políticas públicas de saúde, desenhando a arena política de forma a direcionar as disputas por recursos 4 .

Em 1923, por meio da Lei Eloy Chaves ${ }^{7}$, foi criada a primeira Caixa de Assistência, voltada à categoria dos ferroviários, e que acabou por constituir o marco legal do sistema de previdência - e do sistema de saúde voltado para a atenção de uma categoria profissional e seus dependentes. A partir desse momento, surgem dois tipos de serviços de saúde: as ações de saúde pública, dirigidas a todos, de caráter preventivo, e a medicina previdenciária, à qual tinham acesso apenas os trabalhadores do mercado formal, cujo foco eram os cuidados individuais de cura e tratamento.

No pós-64, a ênfase na assistência hospitalar em detrimento de uma assistência preventiva, aliada à subcontratação de serviços privados, fortemente subsidiados com dinheiro público, impulsiona o setor privado de saúde.

Nas décadas de 1960, 1970 e 1980, as políticas públicas de saúde encontram nas Caixas de Assistência, nos Institutos de Aposentadoria e Pensões, no INPS e depois no Inamps as suas matrizes. Significa dizer que a porta de acesso ao sistema de saúde era o emprego formal. A criação do Inamps afastou a fragmentaridade, mas não ampliou o acesso, mantendo-se o sistema na sua essência meritocrático.

No entanto, o rompimento do modelo meritocrático pretendido com o SUS não foi sucedido por um universalismo distributivo, mas daquilo que Favare ${ }^{5}$ chamou de universalismo excludente: universalismo porque 0 acesso ao sistema não se dá por meio do vínculo com o mercado de trabalho, excludente porque a insuficiência de recursos repele desse sistema todos aqueles que podem ter acesso ao sistema suplementar. A forma de desenvolvimento das políticas públicas gerou, assim, assimetria 
também entre os destinatários dos serviços de saúde: o SUS ficou reservado ao atendimento dos mais pobres.

O abatimento dos gastos com o setor de saúde suplementar - que só é possível aos cidadãos que têm maior capacidade financeira e que, por isso, recolhem Imposto de Renda de Pessoa Física (IRPF); o incentivo para que os empregadores ofereçam o benefício aos seus empregados como vantagem de caráter não remuneratório; e, por fim, e mais recentemente, a expansão dos planos coletivos reservam ao sistema suplementar o quarto da população com maior poder aquisitivo e com maior capacidade de articulação.

A certeza do esgotamento do sistema público caminha lado a lado com outra certeza: a de que, inevitavelmente, mais dia, menos dia, de forma permanente ou esporádica, todos necessitaremos de cuidados de saúde. Ademais, junto com a certeza de que precisamos de atenção à saúde, de que não encontraremos no SUS o cuidado com a presteza necessária (ou desejada), existe outra, a da impossibilidade financeira de custeio direto do cuidado de saúde necessário ou daquele que se percebe por necessário.

Verdadeiramente, não existe uma opção por contratar serviços de saúde: essa adesão vem como uma necessidade premente de cuidado médico ante a insuficiência e ineficácia da assistência à saúde disponibilizada pela rede pública. Ainda que as portas do SUS estejam abertas, os leitos estão ocupados, a agenda já está fechada.

É preciso intervir na linha de cuidado proposto pelas operadoras da saúde suplementar, provocando um realinhamento com a forma de cuidado eleita pelo SUS, e privilegiando - como no SUS - a atenção primária; significa que também na assistência privada é preciso expandir o cuidado para a prevenção de doenças e para a promoção de saúde, o que vem sendo apenas recentemente construído. Por trás disso, o que se pretende é atribuir às operadoras de saúde o papel de gestoras de cuidado.
O primeiro objetivo da agência reguladora é intervir diretamente na regulação do mercado, corrigindo os desvios que são próprios de uma demanda que é inelástica pela sua natureza e que, portanto, não se mostra sensível - não reagente - a variações de preço, o que por si só é suficiente para gerar não um pequeno desequilíbrio, mas uma verdadeira subversão do mercado. Aqui, a participação da ANS na precificação é decisiva para garantir a manutenção dos contratos de saúde para além daqueles momentos em que é conveniente para as operadoras a oferta do serviço.

Entretanto, essa é apenas a primeira etapa desse processo regulatório. As agências reguladoras têm a função de fiscalizar a prestação de serviços públicos por particulares ${ }^{8}$. O interesse público, isto é, a relevância que tem determinado serviço para a coletividade, é que determina a sua natureza, e não o prestador: ainda que se faculte ao particular prestar determinados serviços que se têm por essenciais, essa delegação não retira desses serviços a qualidade de públicos e impõe a regulação e a fiscalização do Estado sobre essas atuações. A Lei n ${ }^{\circ} 7.783 / 89^{9}$ não apenas disciplina o direito de greve, mas reconhece, em seu art. 10, atividades que são essenciais, elencando, entre elas, os serviços de assistência médica e hospitalar. Contudo, esse reconhecimento apenas replica no ordenamento infraconstitucional o pertencimento que tem a saúde como direito fundamental constitucionalmente amparado.

O contexto de privatizações e de flexibilização de monopólios experimentado a partir da metade dos anos 1990 refletiu um redirecionamento do papel do Estado, que deixou de exercer diretamente determinadas atividades tidas por essenciais, delegando-as ao particular, e assumiu, a partir de então, o compromisso regulatório, em uma verdadeira mudança de paradigma da sua atuação: deixou de ser executor e passou a ser fiscal, trazendo para o núcleo da atividade regulatória o policentrismo decisório - imparcialidade política, tecnicidade e autonomia ${ }^{10}$. 
Os múltiplos papéis exercidos pelos vários tipos de atores que participam do sistema particular de saúde criam uma tessitura de relações não linear e fazem surgir um sem-número de situações que possivelmente irão determinar a qualidade do serviço e a linha do cuidado ao paciente, impulsionando a regulação para além do aspecto financeiro desses contratos.

Significa que o olhar e o atuar da ANS tem de ser dirigido ao cuidado proposto pela saúde suplementar, e não apenas para os contratos de prestação de serviços em saúde suplementar, trazendo para dentro da regulação o seu verdadeiro significado, e desenhando a saúde suplementar a partir dos mesmos princípios que informam o SUS, dessa forma concretizando, por meio da regulação, a integralidade da atenção à saúde trazida pela Constituição, e fazendo prevalecer, mesmo nas relações contratuais entre entes privados, o interesse público.

Existem outros lugares para além da precificação dentro das relações privadas de saúde que também precisam ser visitados pelas agências reguladoras, porque é possível - e eu diria provável - que a remuneração de hospitais e profissionais de saúde interfira na linha de cuidado ao paciente.

A incorporação de tecnologias e a fragmentação do cuidado caminham juntas como elementos de precificação dos planos, mas também de remuneração dos profissionais credenciados, intervindo diretamente na linha de cuidado, o que torna obtusa a escolha da agencia reguladora de não visitar esse lugar porque, no final, não se trata apenas de remuneração, mas da qualificação do setor de saúde suplementar.

Da mesma maneira que a forma de remuneração vem determinando a quantidade de exames, a remuneração por procedimento vai induzir a uma quantidade maior de procedimentos (nem sempre necessários) e a um número maior de consultas. Esse é o cuidado hoje praticado pelas operadoras de saúde: fragmentado, muitas vezes intervencionista e hospitalocêntrico, que incorpora com agilidade novas tecnologias.
Para além do argumento da insuficiência do Estado, da baixa capacidade regulatória, existe a questão do relacionamento entre público e privado não só pelos atores que atuam no sistema, mas pelo caminho dos recursos financeiros entre esses lugares; a dicotomia que vem sendo sugerida entre os sistemas público e privado reduz a visibilidade da zona de interseção, afasta a confluência entre esses sistemas e, por isso, exclui deliberadamente da pauta debates sobre fluxo de pacientes e financiamento público tanto de demanda como de oferta de serviços.

\section{Considerações finais}

É impossível dissociar a opção por um ou por outro sistema de saúde das transformações da concepção de cidadania em um caminhar que deslocou os indivíduos de sujeitos de direitos para objeto de proteção; que deslocou o eixo de proteção de relações jurídicas para situações que podem ser juridicamente relevantes ou não.

A cidadania, que inicialmente demandou o reconhecimento e o exercício de direitos políticos como limitação do Estado, em uma relação vertical - em que as desigualdades entre os cidadãos não era uma variável a ser considerada -, impõe a atuação do Estado também nas relações horizontais, isto é, entre cidadãos, entre pessoas que devem ser tuteladas e protegidas, não de forma igualitária, mas equitativa, deslocando o conceito de igualdade de uma perspectiva meramente formal para uma igualdade de fato. Ideias, sociedades e o próprio homem são um constante porvir, em uma trajetória que tem um marco inicial, mas que nunca se exaure, porque o tempo do humano é o gerúndio.

Reconhecer que o atual sistema brasileiro traz consigo marcas do modelo institucional anterior possibilita entender como e por que um sistema que se coloca com a pretensão de ser único, paradoxalmente recebe e subsidia um sistema paralelo: porque os desenhos das políticas públicas alteram e são alterados pelos 
processos políticos, afetam e são afetados pelas opções institucionais anteriores: ainda que o paradigma escolhido seja o do universalismo inglês, a nossa tendência de estruturação se volta para o sistema americano.

As demandas trazidas aos juízes que atuam em varas cíveis e que têm como pano de fundo os contratos de prestação de saúde são demandas privadas, contratuais, de consumo, mas são também demandas que trazem um interesse público latente; são demandas que só podem ser julgadas apropriadamente se estiverem dentro da perspectiva constitucional, em que cidadania e existência se confundem, misturam-se e constroem juntas o humano.

Nas relações entre os usuários do sistema privado e as operadoras dos planos de saúde, o contrato é apenas o paradigma inicial: ele serve de moldura para a tessitura das relações entre operadoras e usuários, mas as relações que ali se desenvolvem não podem ser limitadas exclusivamente à esfera do privado e têm de ser analisadas também sob a perspectiva constitucional.

O sistema constitucional não é apenas um norte, uma referência, mas sim a verdadeira perspectiva de todo o sistema de direito, que não pode se desenvolver para além ou fora da Constituição, como sistema paralelo, assim como as políticas públicas de saúde não podem se afastar dessa mesma matriz constitucional. Dentro dessa perspectiva, o estudo da saúde e das políticas de saúde (de prevenção e promoção), os cuidados de saúde, impõem-se como forma de afirmação do indivíduo em sua plenitude.

Com essas considerações, entendemos que o olhar, a regulamentação e a atuação da agência de saúde (e assim do próprio Estado) têm de alcançar inclusive as relações do setor privado, porque a saúde, ainda que prestada por particular, é pública. Sempre! É a perspectiva (constitucional) que dá a dimensão do objeto e valora a saúde como bem público, de todos e de cada um individualmente.

A proposta do presente estudo foi fazer perceber na interseção desses sistemas não um contraponto, mas uma verdadeira simbiose em que se constroem, limitam-se e ampliam-se público e privado, garantindo a todos os usuários do SUS, usuários da rede privada e usuários do SUS, cidadãos de um Estado comum, indivíduos que se colocam perante esse Estado. É preciso retirar do jurídico os antolhos para que o direito se revele, um direito que não pode ser dado, mas que é construído na exata medida em que vai sendo vivido; um direito que é gerúndio, para cidadãos que são, no tempo presente, para que possam ser, no tempo futuro, plenos apesar de e com as suas limitações, reconhecendo o ontológico e o valorativo em cada ação, em cada omissão, em cada escolha.

\section{Colaboradores}

Gomes APA (0000-0003-2512-7107)* e Maciel EMG (0000-0002-9095-3141)* contribuíram igualmente na elaboração do manuscrito. 


\section{Referências}

1. Brasil. Lei nº 8.078, de 11 de setembro de 1990. Código de Defesa do Consumidor. Dispõe sobre a proteção do consumidor e dá outras providências [internet]. Diário Oficial da União. 12 Set 1990. [acesso em 2017 set 19]. Disponível em: http://www.planalto.gov. br/ccivil_03/Leis/L8078.htm.

2. Brasil. Lei no 9.656, 3 de junho de 1998. Dispõe sobre os planos e seguros privados de assistência à saúde [internet]. Diário Oficial da União. 4 Jun 1998. [acesso em 2017 set 11]. Disponível em: https://portal.cfm.org.br/index.php?option=com_content\&vi ew=article $\&$ id =21722:lei-96561998-dispoe-sobre-os-planos-e-seguros-privados-de-assistencia-a-saude \&catid=66:leis $\&$ Itemid=34.

3. Brasil. Constituição da República Federativa do Brasil [internet]. Brasília, DF: Senado Federal; 1988. [acesso em 2018 set. 15]. Disponível em: http://www.planalto.gov.br/ccivil_03/constituicao/constituicao.htm.

4. Sestelo JAF, Souza LEPF, Bahia L. Saúde suplementar no Brasil: abordagens sobre a articulação público/privada na assistência à saúde. Cad. Saúde Pública. $2013 ; 29(5): 851-66$.

5. Menicucci TMG. Público e privado na política de assistência à Saúde no Brasil: atores, processos e trajetórias. Rio de Janeiro: Fiocruz; 2007.

6. Faveret Filho P, Oliveira PJ. A Universalização excludente: reflexões sobre as tendências do sistema de saúde [internet]. Planejamento e políticas públicas. 1990. [acesso em 2017 out 16]; 3:139-162. Disponível em: http://repositorio.ipea.gov.br/handle/11058/7358.

7. Brasil. Lei Eloy Chaves. Caixa de aposentadorias e pensões no setor ferroviário [internet]. Brasília, DF: Senado Federal; 1923. [acesso em 2017 out 16]. Disponível em: https://www12.senado.leg.br/noticias/ especiais/arquivo-s/primeira-lei-da-previdencia-de-1923-permitia-aposentadoria-aos-50-anos.

8. Barroso LR. Agências reguladoras. Constituição, transformações do estado e legitimidade democrática. Rio de Janeiro: RDA; 2002.

9. Brasil. Lei no 7.783 , de 28 de junho de 1989. Dispõe sobre o exercício do direito de greve, define as atividades essenciais, regula o atendimento das necessidades inadiáveis da comunidade, e dá outras providências [internet]. Diário Oficial da União. 29 Jun 1989. [acesso em 2017 out 16]. Disponível em: http:// www.planalto.gov.br/ccivil_03/LEIS/L7783.htm.

10. Binenbjoim G. Palestra: Agências Reguladoras Independentes, TCE/RJ [internet]. 2010. [acesso em 2017 out 11]. Disponível em: www.tce.rj.gov.br/web/ecg/ seminarios/2010/controle-externo-e-agencias-reguladoras-de-servicos-publicos.

Recebido em 15/08/2019

Aprovado em 08/11/2019

Conflito de interesses: inexistente

Suporte financeiro: não houve 